\title{
Constituição identitária do professor do ensino técnico de nível médio
}

\author{
Identity constitution of high school technical education teacher
}

\section{Constitución de la identidad del profesor de educación media técnica}

\author{
Lima, Viviane Cardoso Cunha de ${ }^{1}$ (São Paulo, SP, Brasil) \\ ORCID ID: https://orcid.org/0000-0003-3622-6223 \\ Nacarato, Adair Mendes ${ }^{2}$ (Itatiba, SP, Brasil) \\ ORCID ID: https://orcid.org/0000-0001-6724-2125
}

\begin{abstract}
Resumo
Este texto apresenta um recorte de uma pesquisa de mestrado realizada com professores de ensino técnico nível médio que atuam em escolas do Centro Paula Souza, no estado de São Paulo. Trata-se de uma pesquisa de abordagem qualitativa cujos dados foram produzidos com entrevistas narrativas feitas com cinco docentes (três do sexo masculino e duas do feminino), de diferentes unidades escolares. Objetiva-se, neste texto, buscar indícios da constituição da identidade desse profissional a partir da experiência vivida e percebida por ele na prática docente. Desses cinco docentes, dois eras licenciados, os demais tiveram formação técnica e não tinham intenção de ser professores. No entanto, ao ingressarem na rede de ensino foram se identificando com a profissão dadas as boas condições de trabalho docente; eles se sentem valorizados na instituição. Eles se constituíram professores no exercício da profissão docente e constroem a identidade profissional nas relações interpessoais com alunos e colegas. $O$ ambiente institucional favorece a realização de trabalhos coletivos e os professores se sentem com status por participar da rede.
\end{abstract}

Palavras-chave: Identidade profissional. Ensino técnico. Professor de educação tecnológica.

\begin{abstract}
This text presents an excerpt from a master's research carried out with high school technical teaching teachers who work in schools at the Paula Souza Center, in the state of São Paulo. It is a qualitative research whose data were produced with narrative interviews with five teachers (three male and two female), from different school units. The goal of this text is to seek evidence of the constitution of the identity of these professionals from the experience lived and perceived by them in teaching practice. Within these five professors, two had a college degree, the others had only technical training and had no intention of becoming teachers. However, when they entered the education network, they became identified with the profession due to the good teaching work conditions; they feel valued in the institution. They became teachers in the exercise of the teaching profession and have built professional identity in interpersonal relationships with students and colleagues. The institutional environment favors the performance of collective work and teachers feel they have a certain social status and that they are part of the network.
\end{abstract}

Keywords: Professional identity. Technical education. Technological education teacher.

\section{Resumen}

Este texto presenta un extracto de una investigación de maestría realizada con docentes de educación media técnica que trabajan en escuelas del Centro Paula Souza, en el estado de São Paulo. Es una investigación cualitativa cuyos datos fueron producidos a partir de entrevistas narrativas con cinco maestros (tres hombres y dos mujeres) de diferentes unidades escolares. El objetivo de este texto es buscar evidencia de la constitución de la identidad de este profesional a partir de la experiencia vivida y percibida por él en la práctica docente. De estos cinco profesores, dos eran docentes licenciados, los otros tenían capacitación técnica y no tenían intención de ser maestros. Sin embargo, cuando ingresaron a la red educativa, gradualmente pasaron a identificarse con la profesión debido a las buenas condiciones de trabajo docente; se sienten valorados en la institución. Se convirtieron en maestros en el ejercicio de la profesión docente y construyen su identidad profesional en las relaciones interpersonales con estudiantes y colegas. El ambiente institucional favorece la realización de tareas colectivas y los docentes sienten que tienen estatus por participar en la red.

\footnotetext{
1 Professora de Ensino Médio Técnico da Rede Pública do Estado de São Paulo. vcclima@hotmail.com

2 Docente da Universidade São Francisco, campus de Itatiba, junto ao Programa de Pós-Graduação Stricto Sensu em Educação e ao curso de Pedagogia. ada.nacarato@gmail.com 
Palabras clave: Identidad profesional. Educación técnica. Profesor de educación tecnológica.

\section{Introdução}

O presente artigo é o recorte de uma dissertação de mestrado que tem como foco a constituição identitária de professores que atuam no ensino profissionalizante, nível médio, da rede de escolas do Centro Paula Souza (CPS), no estado de São Paulo. Essa instituição foi criada pelo Decreto-Lei de 6 de outubro de 1969 (SÃO PAULO, [20--]). Em 1970, iniciou as atividades com o nome de Centro Estadual de Educação Tecnológica de São Paulo (CEET), oferecendo três cursos na área de Construção Civil (Movimento de Terra e Pavimentação, Construção de Obras Hidráulicas e Construção de Edifícios) e dois na área de Mecânica (Desenhista Projetista e Oficinas). Em 1969, o CPS nasceu com o propósito de oferecer cursos superiores de Tecnologia, mas, no decorrer das décadas, além desses, passou a contar com a educação profissional em nível médio, expandindo, assim, seus cursos tecnológicos e técnicos para todas as regiões do Estado.

De acordo com dados encontrados na homepage do Centro Paula Souza, a rede está presente em aproximadamente 300 municípios paulistas, administrando 223 Escolas Técnicas (Etec), 73 Faculdades de Tecnologia (Fatec) estaduais e a Administração Central, com 292,8 mil alunos em cursos técnicos de nível médio e superior. As Etec atendem mais de 211 mil estudantes nos ensinos técnico, médio e técnico integrado ao médio, com 148 cursos técnicos para os setores industrial e agropecuário e para o segmento de serviços. Foi com docentes dessa rede de ensino que esta investigação foi realizada.

A pesquisa contou com cinco professores que atuam nessa rede e que, a priori, foram contratados por prazo determinado e, a posteriori, por meio de aprovação em concurso público, tiveram seus contratos alterados para prazo indeterminado. Havia, por parte da pesquisadora - primeira autora do texto - uma inquietude sobre esse sistema de contração, considerando que essa ainda é uma prática nessa rede de ensino. O que leva esses professores a assumirem aulas com contratos temporários na instituição? Esse tipo de contratação interfere nas condições de trabalho ou na constituição profissional? Nasceu, assim, a mobilização para a realização da pesquisa.

O recorte aqui apresentado visa a buscar indícios da constituição da identidade desse profissional a partir da experiência vivida e percebida por ele na 


\section{Revista Labor}

Programa de Pós-graduação em Educação, Universidade Federal do Ceará

Fortaleza-CE-Brasil

prática docente. Para isso, partimos da análise da trajetória profissional dos entrevistados, considerando os depoimentos desses professores no momento de uma entrevista narrativa. Inicialmente fazemos algumas reflexões teóricas sobre a identidade profissional docente; em seguida, apresentamos os caminhos metodológicos da pesquisa; na sequência, expomos a análise dos dados. A partir dos achados deste estudo, tecemos algumas reflexões finais.

\section{A identidade profissional docente}

O conceito de identidade docente é complexo, e há diferentes perspectivas teóricas para discuti-lo. Procuramos expor algumas delas, de forma a contribuir para o processo analítico dos dados. Podemos abordar a identidade pessoal e a profissional; no caso desta pesquisa, tratamos da profissional docente.

Como nosso trabalho faz aproximações com os estudos biográficos, ao utilizarmos a entrevista narrativa, vamos adotar o que Bolívar (2006) denomina de identidade "biográfico-narrativa". Nessa perspectiva, a identidade pessoal está relacionada ao modo como narramos nossa vida. Responder à pergunta "quem sou eu" remete a contar uma história de vida. É a narrativa que permite a unidade, a continuidade temporal e a conexão entre os acontecimentos que marcaram nossas trajetórias.

As pessoas constroem, assim, sua identidade individual fazendo um autorrelato, que não é apenas recordação do passado, mas também um modo de o recriar, em uma tentativa de descobrir um sentido e inventar o eu, em modos que podem ser socialmente reconhecíveis. (BOLÍVAR, 2006, p. 34, tradução nossa ${ }^{3}$ )

A narrativa possibilita esse fio condutor de nossa vida, mediando o passado, o presente e o futuro, atribuindo sentidos ao passado e se projetando para o futuro.

A identidade é, pois, uma realização discursiva: ser identificado como esta ou aquela pessoa, com alguns atributos, autorreferenciar-se, adquirindo um sentido de individualidade, só é possível no relato narrativo. Por isso a identidade é um produto da narrativa. (BOLíVAR, 2006, p. 37, tradução nossa $\left.{ }^{4}\right)$.

\footnotetext{
3 "Las personas construyen, así, su identidad individual haciendo un autorrelato, que no es sólo recuerdo del pasado sino un modo de recrearlo, en un intento de descubrir un sentido e inventar el yo, en formas que puedan ser socialmente reconocibles."

4 "La identidad es, pues, una realización discursiva: ser identificado como esta o aquella persona, con unos atributos, autorreferenciarse, adquiriendo un sentido de individualidad, sólo es posible en el relato narrativo. Por eso la identidad es un producto de la narrativa."
} 
Tais perspectivas são coerentes com a entrevista narrativa. Nela, 0 depoente constrói sua história, narra e produz sentido às experiências vividas.

Além da identidade pessoal, há que se considerar a identidade profissional, ligada ao mundo do trabalho. Mas ela não se separa da identidade pessoal, pois

\begin{abstract}
a identidade profissional é uma construção singular, própria de cada docente, ligada a sua história pessoal e aos múltiplos pertencimentos que carrega consigo (sociais, familiares, escolares e profissionais). Nesse sentido, a construção identitária é um processo biográfico contínuo, e a identidade, como manifestou Dubar (2000), pode ser vista como o resultado de uma transação entre uma identidade herdada e uma identidade a que se aspira ou é imposta pela situação atual. (BOLíVAR, 2006, p. 46-47, grifos do autor, tradução nossa ${ }^{5}$ )
\end{abstract}

Para Dubar (2012, p. 358, grifos do autor), a identidade profissional do sujeito está conectada com a socialização profissional, com a inserção no mundo do trabalho. Por conseguinte, a identidade está em constante processo de constituição.

\begin{abstract}
Socialização profissional é, portanto, esse processo muito geral que conecta permanentemente situações e percursos, tarefas a realizar e perspectivas a seguir, relações com outros e consigo (self), concebido como um processo em construção permanente. É por esse e nesse "drama social do trabalho" que se estruturam mundos do trabalho e que se definem os indivíduos por seu trabalho.
\end{abstract}

Nessa construção, o profissional vai se apropriando de modos de ser e de fazer que são característicos da posição que ocupa. De acordo com Bolívar (2006, p. 30, tradução nossa ${ }^{6}$ ), "a identidade do professor (teacher self) é construída e reconstruída mediante as interações sociais que os professores têm nos contextos particulares em que atuam." A identidade docente se constrói e se reconstrói em consonância com o ambiente escolar em que o professor atua. Essa construção começa em seus primeiros contatos com a escola, quando ele vai se apropriando dos modos de ser professor, e é contínua, mantém-se ao longo da vida profissional de uma pessoa. Como afirma Marcelo (2009), na trajetória estudantil estamos em contato durante muitas horas com diferentes professores e modos de conduzir uma aula; são aprendizados constitutivos da identidade do futuro docente.

\footnotetext{
5 "La identidad profesional es una construcción singular, propria de cada docente, ligada a su historia personal y a las múltiples pertenencias que arrastra consigo (sociales, familiares, escolares y profesionales). En este sentido, la construcción identitaria es un proceso biográfico continuo y la identidad, como puso de manifiesto Dubar (2000), puede ser vista como el resultado de una transacción entre una identidad heredada y una identidad a la que se aspira o impuesta por la situación actual."

6 "la identidad docente (teacher self) se construye y reconstruye mediante las interacciones sociales que los profesores tienen en los contextos particulares en que actúan." 
Segundo Brunet (1992, p. 125), são "os atores no interior de um sistema que fazem da organização aquilo que ela é." Portanto, a identidade docente é construída à medida que o profissional se compromete com a profissão docente e assume que é um educador. É interessante perceber semelhanças com nós mesmos no outro, isso nos possibilita um movimento significativo de repensar, construir e nos reconstruir.

A docência é uma prática que lida com os alunos, os professores, a direção da escola, a coordenação pedagógica, a comunidade, os pais e os familiares. No caso do docente, ele também deve lidar consigo mesmo. É uma profissão com ampla visibilidade por várias pessoas e cenários. A identidade profissional docente se constitui como uma interação entre a pessoa e suas experiências individuais e profissionais (MARCELO, 2009, p. 1).

Tal identidade pode ser vista sob várias óticas. Podemos refletir, por exemplo, sobre como o docente é, como ele pensa em ser ou como ele é visto.

\begin{abstract}
E visto que os professores são fundamentais, precisamos que nossos sistemas educativos sejam capazes de atrair os melhores candidatos para se tornarem docentes. Necessitamos de boas políticas para que a formação inicial desses professores lhes assegure as competências que vão precisar durante sua longa, flexível e variada trajetória profissional. E a sociedade necessita de bons professores, cuja prática profissional cumpra os padrões profissionais de excelência que assegurem o compromisso do respeito ao direito que os alunos têm de aprender. (MARCELO, 2009, p. 2-3)
\end{abstract}

Reconhecemos, além disso, com Bolívar (2006), que a identidade profissional docente também se constrói de acordo com o nível de ensino no qual o professor atua e, muitas vezes, no caso dos professores especialistas, com a própria disciplina que ministram. Esses professores especialistas "são professores de algo, e esse algo (profissional, como denotam as expressões 'sou de matemática' ou 'sou de inglês') é um fator crítico em seus modos de ver e fazer, distinto entre umas matérias e outras." (BOLÍVAR, 2006, p. 54, grifos do autor, tradução nossa7). Ser professor de um curso técnico acarreta singularidades para a identidade profissional.

Neste trabalho, partimos do pressuposto de que a identidade se constitui nos múltiplos contextos vividos pelos professores e pelas condições de trabalho. As relações que os docentes estabelecem com os demais atores da escola vão acrescentando novos elementos, reorganizando outros, num movimento contínuo. 


\title{
Caminhos metodológicos da pesquisa
}

A pesquisa, de abordagem qualitativa, contou com a participação de cinco depoentes, que são professores de ensino médio e técnico, sendo três do sexo masculino e dois do sexo feminino. Esses docentes atuam em diferentes unidades do CPS. Os dados foram produzidos a partir de entrevistas narrativas realizadas com cada docente, as quais foram transcritas e textualizadas.

Optamos por entrevistas narrativas (JOVCHELOVITCH; BAUER, 2005) como procedimento de produção de dados, visto que elas se configuram como importantes dispositivos na produção de dados relativos a trajetórias profissionais. A narrativa tem o poder de ressignificar as práticas docentes. Podemos dizer que a narrativa é um elemento básico de comunicação humana e é inerente à vida, pois, sem narrativa, não se tem história; se a história nasce de narrativas, admitimos que as narrativas são infinitas em suas formas e variedades.

\begin{abstract}
$\mathrm{Na}$ verdade, as narrativas são infinitas em sua variedade, e nós as encontramos em todo o lugar. Parece existir em todas as formas de vida humana uma necessidade de contar; contar histórias é uma forma elementar de comunicação humana $e$, independentemente do desempenho da linguagem estratificada, é uma capacidade universal. Através da narrativa, as pessoas lembram o que aconteceu, colocam a experiência em uma sequência, encontram possíveis explicações para isso, e jogam com a cadeia de acontecimentos que constroem a vida individual e social. (JOVCHELOVITCH; BAUER, 2005, p. 92)
\end{abstract}

Cada entrevista narrativa é individual, única, particular. Ela vai além do esquema pergunta-resposta. Ela parte de um roteiro mais amplo, preparado pelo pesquisador, apoiado na ideia de escutar a história contada por um depoente, numa modalidade narrativa.

No caso desta pesquisa, as entrevistas narrativas foram audiogravadas e transcritas. Houve a devolutiva aos participantes, no intuito de que eles fizessem as correções e as complementações que julgassem necessárias. O projeto de pesquisa foi aprovado pelo Comitê de Ética da universidade e foi assegurado o anonimato tanto dos participantes quanto das escolas nas quais eles atuam. Os pseudônimos utilizados para nomear cada professor foram escolhidos pelos depoentes e são estes: Panda, Cristal, Sócrates, Joaninha e Águia.

Os cinco depoentes aceitaram nosso convite para conceder uma entrevista narrativa. Inicialmente, contatamos a Diretoria de Serviço - área administrativa de 
algumas Escolas Técnicas do estado de São Paulo - e solicitamos indicações para depoentes contratados nessas condições. A partir dessas informações, identificamos os professores e convidamo-los para participarem da pesquisa.

Os entrevistados são profissionais, que atuam na capital e no interior, das Escolas Técnicas do estado de São Paulo. Tivemos como critério de escolha profissionais de diferentes unidades; assim, podemos ter maior diversidade de informações. Todos eles foram contratados como temporários, efetivando-se posteriormente. Na sequência, apresentamos de forma resumida cada um dos participantes.

Panda ocupa emprego público permanente de professor de ensino médio e técnico e está designado como coordenador pedagógico, na mesma Escola Técnica. É formado como técnico em Informática e bacharel em Análise de Sistemas.

Cristal está afastada do emprego público permanente de professora de ensino médio e técnico e tem uma vaga em confiança de diretora de serviço da área administrativa, na mesma Escola Técnica. É graduada em Ciências Exatas, Matemática, Física e Engenharia Civil, possui ainda especialização em Matemática e Engenharia Civil.

Sócrates é um professor que atuava como diretor de Escola Técnica, solicitou desligamento para ocupar cargo público, mas ainda trabalha na vaga permanente de professor de ensino médio e técnico. É técnico em Eletrônica, bacharel em Análise de Sistemas, licenciado em Processamento de Dados, especialista em Administração de Empresas e mestre em Educação.

Joaninha ocupa o emprego público permanente de professora de ensino médio e técnico e, na mesma rede, também é professora de ensino superior. É formada em Fisioterapia, licenciada em Letras e mestre em Movimento, na área de Biodinâmica Humana (Educação Física).

Águia está afastado do emprego público permanente de professor de ensino médio e técnico, ocupa cargo em confiança de diretor de Escola Técnica e acumula, na mesma rede de ensino, a função de professor de ensino superior. É técnico em Compatibilidade, bacharel em Biologia, especialista em Administração Escolar, Direito Ambiental, Vigilância Sanitária e Epidemiológica, e mestre em Recursos Hídricos. 
O processo analítico envolveu muitas idas e vindas ao material produzido, de modo a encontrar indícios de como a identidade profissional foi se constituindo a partir da vivência na prática. Essa foi uma das categorias de análise da pesquisa mais ampla. As vozes dos depoentes entrecruzam-se com as nossas vozes e com as dos autores tomados como referência. As reflexões teóricas foram produzidas a partir do que emergiu nas narrativas dos professores.

\section{A constituição identitária do professor que atua no CPS}

Nos dados produzidos para esta pesquisa, a partir das narrativas dos docentes, foi possível identificar que eles têm constituído sua identidade ao longo da trajetória profissional.

A identidade assume-se, assim, não como uma coisa, mas como um processo onde o reconhecimento, a valorização, a confirmação ou desconfirmação dos outros nos impele a uma negociação interna (subjectiva) ou externa (objectiva) nas configurações identitárias que assumimos. (SANTOS, 2005, p. 127)

Do professor que atua no CPS, especificamente no curso técnico profissionalizante, exige-se que seja um profissional técnico, ou seja, que possua formação em área específica e atenda as exigências necessárias para lecionar as disciplinas para as quais é contratado. Essa talvez seja uma das diferenças desse profissional em relação aos docentes que não atuam em cursos técnicos nível médio. Nem todos os professores, quando contratados, tinham o curso de licenciatura para atuar na docência, conforme exige a legislação atual.

Para muitos depoentes, ser professor não era a primeira opção; eles foram levados pela vida, nem imaginavam ser professores, despertaram algum interesse após o contato com a docência ou tiveram dificuldades de empregabilidade. A maioria dos entrevistados possui cursos técnicos; alguns têm mais de uma graduação; outros, especializações, licenciatura e mestrado. Grande parte deles declarou pretensão por outra formação, mas, devido às dificuldades de ordem financeira ou de empregabilidade, tiveram que fazer outras escolhas profissionais.

Joaninha, por exemplo, após terminar a formação em Fisioterapia - curso que optou por fazer após cinco anos tentando Medicina - e mestrado na área, não conseguindo mais emprego nesse campo, iniciou outra graduação, em Letras. Em sua entrevista, ela narrou esse momento de sua vida: "não vou procurar mais nada de 
Fisioterapia, porque não está dando certo. Então eu vou fazer, aí qualquer coisa eu faço licenciatura, faço bacharelado e vou dar aula." ${ }^{8}$ (Joaninha, EN, 2018).

$\mathrm{E}$ foi exatamente o que aconteceu quando ela fez o processo seletivo para trabalhar na Etec, iniciando sua carreira em 2010. Embora o magistério não tivesse sido sua primeira opção, ela recordou-se de sua aproximação positiva com a profissão:

eu acho que foi também porque minha mãe era professora, minha mãe era professora de Português para estrangeiro. Então eu já tenho uma professora dentro de casa. [...] eu sempre gostei de brincar de professora, eu sempre gostei de ensinar as outras pessoas, sempre senti que tinha essa facilidade. (Joaninha, EN, 2018)

\section{Como afirma Dominicé (2010, p. 86-87, grifo do autor),}

as pessoas citadas são frequentemente as que exerceram influência no decurso da existência. Visto que a narrativa não é construída como um itinerário relacional, essas pessoas não dão lugar a uma descrição detalhada. São evocadas à medida que participam num momento importante do percurso de vida. Pais, professores, amigos, "mentores", patrões, colegas, companheiros, amantes marcam a cronologia da narrativa [...]. Na narrativa biográfica, todos que são citados fazem parte do processo de formação.

Joaninha talvez só tenha se dado conta dessa influência familiar no momento da produção da narrativa, o que corrobora as ideias dos autores tomados como referência, de que, a produção de narrativas é um momento de reflexividade e tomada de consciência do narrador sobre sua trajetória. De modo geral, os depoentes tiveram apoio e incentivo familiar para estudar. Águia (EN, 2018), por exemplo, destacou:

A minha família não estudou. Porque vieram de roça. Uma estrutura... então não estudaram. Mas minha mãe foi incentivadora de estudar. [...] A minha mãe corria atrás da gente na rua para ir estudar naquela época. Então, a minha mãe foi a grande pessoa que fomentou a estudar. A minha mãe e a minha irmã. Então a gente viu que ela acabou ajudando na formação.

Outros depoentes expuseram lembranças da escola. Panda (EN, 2018), por exemplo, ao lembrar de sua época como aluno da Etec, narrou:

Eu fui um aluno que sempre questionei muito, eu adorava perguntar. Eu era aquele aluno que o professor pedia para fazer alguma coisa, eu tentava sempre fazer um pouco mais do que aquilo. Ele falava vamos desenvolver um programa que vai somar dois números, para a gente aprender como funciona. Eu já fazia de somar, multiplicar, dividir, dar os mínimos do número, porque eu gostava, eu achava que, nossa, dá para fazer isso, então dá para fazer mais do que isso. Eu acho que isso é uma coisa que eu levo muito na vida hoje.

${ }_{8}^{8}$ As falas dos depoentes estão grafadas em itálico para que sejam diferenciadas das citações teóricas. 
Panda (EN, 2018) também se referiu ao papel que os professores da Etec tiveram em sua formação:

\begin{abstract}
Eu tenho um professor aqui até hoje, o professor $R V$, que ele olhou para mim, quando eu era aluno do técnico aqui da Etec, e falou assim: "Você é tão chato, incomodando a gente que você vai virar professor e, pior que isso, vai virar professor e vai vir dar aula aqui ainda." E eu sempre brinco: "Praga de professor pega." E a praga dele pegou, porque realmente eu fui, eu me graduei, eu virei professor, eu tive oportunidade de voltar para a Etec, uma ex-professora minha me avisou que ia ter processo seletivo, eu participei do processo seletivo, hoje trabalho com os meus ex-professores.
\end{abstract}

A identidade profissional não se desloca da identidade pessoal. Se Panda sempre foi um estudante questionador, hoje ele é um professor questionador, apontando indícios de como a constituição profissional traz as marcas das trajetórias vividas. Para Bolívar (2006), a identidade profissional tem um núcleo, compartilhado pelos membros de um grupo profissional; e esse núcleo é relativamente estável, embora possa sofrer transformações a partir das novas exigências postas aos docentes. Como afirmam Tardif e Raymond (2000, p. 223, grifos dos autores),

quando os professores atribuem o seu saber-ensinar à sua própria "personalidade" ou à sua "arte", parecem estar se esquecendo justamente de que essa personalidade não é forçosamente "natural" ou "inata", mas é, ao contrário, modelada ao longo do tempo por sua própria história de vida e por sua socialização.

Sócrates (EN, 2018), por sua vez, nunca teve intenção de ser professor:

Nunca tive desde criança essa intenção. Gostava muito de Eletrônica, de construir circuito, projetos, mas professor nunca me interessei. Depois, trabalhando junto na Etec de auxiliar de laboratório, vendo os professores, aí me interessei e comecei a dar aula. Tanto que me ajudou muito, que ainda eu dou aula de Informática e de Eletrônica também.

Docentes com o perfil de Sócrates é comum nos cursos da Etec, ou seja, profissionais técnicos que se tornam professores depois do ingresso na instituição. No caso dele, diferente dos demais participantes da pesquisa, seu desejo pelo magistério surgiu atuando na própria instituição, o que o levou a um curso de licenciatura, também na área técnica.

Cristal também não tinha intenção de ser professora. Ela explicou:

Alguns amigos davam aula já. E como não havia professor de Física e nem de Matemática tão facilmente disponíveis, eles pediram para eu vir para cá: "Venha dar aula, nós estamos precisando de professor." Conhecia o diretor na época também, que havia sido meu professor. Então, foi o professor $M$, ele foi meu professor, eu acho que no segundo grau, ali no ensino médio: 
"Não, venha para cá." E vim. Por isso, eu acabei gostando de dar aula e acabei ficando por aqui. (Cristal, EN, 2018)

Assim como Joaninha passou por outros espaços profissionais, Sócrates e Águia circularam por outros ambientes. Sócrates, técnico em Eletrônica, cursou Análise de Sistemas, fez especialização em Administração de Empresas, formou-se no curso de licenciatura em Processamento de Dados por meio da Fatec, no Centro Paula Souza, e, por fim, realizou mestrado em Educação. Com isso, concluiu que sua vida estudantil “passa por tudo”, Eletrônica, Informática, Administração e Educação.

Águia, por sua vez, além do ensino profissionalizante, graduou-se em Biologia e fez pesquisa científica, mas não quis permanecer na área. Posteriormente, fez pós-graduação em Administração Escolar, Direito Ambiental, Vigilância Sanitária e Epidemiológica, e, ademais, tem mestrado em Recursos Hídricos. Ou seja, ele passou por um processo de busca até se encontrar profissionalmente. Águia sempre teve interesse em conhecer a área de aplicabilidade dos conhecimentos que adquiria, nunca desejou ser especialista em um só campo. Podemos dizer que ele sempre buscou sua formação intelectual, tal como defende Josso (2010, p. 317) ao definir

a formação intelectual como um desenvolvimento das capacidades reflexivas, uma integração de referenciais de pensamento e de ação até então ignorados ou desconhecidos, um desenvolvimento de sua capacidade de observação e de investigação subordinada à melhoria individual e coletiva da qualidade de vida.

Não existe um "eu" pronto e definido; muito pelo contrário, o "eu" está sempre em mudança, transformando-se e constituindo-se constantemente, num processo de fazer-se e refazer-se, de busca, encontro e desencontro. Trata-se de assumir a inconclusão do ser humano, na perspectiva freireana (FREIRE, 2019). A vida segue de acordo com o meio em que vivemos, dos grupos sociais dos quais participamos, de nossas vivências acadêmicas, políticas e econômicas, mas também tem suas raízes na formação familiar e nas escolhas que fazemos a partir de todas essas experiências. Portanto, nossa identidade é narrativo-biográfica. "A identidade profissional docente é, também, fruto de um amplo processo de socialização que culmina no exercício da profissão e na assunção da cultura profissional própria que 
faz com que o professor se sinta e seja reconhecido como tal." (BOLÍVAR, 2006, p. 51, tradução nossa ${ }^{9}$ ).

A identidade profissional vai sendo constituída no exercício da profissão e nas relações interpessoais que estabelecemos com os diferentes atores da escola. Uma questão que emergiu das entrevistas é a própria concepção de profissão docente.

Na fala de Panda, "ser professor não é uma profissão, ser professor é ter um dom." Para ele, há pessoas que tomam a docência como um "bico", uma tentativa de ser professor. Segundo o entrevistado, isso faz com que a aula dada não seja prazerosa, que não seja ministrada com o carinho que a educação merece. Panda também frisa que ele possui o "dom" de ser professor.

A profissão docente nos faz questionar: "o que serei eu sem meus alunos que me constroem a cada dia?" (FREITAS, 2013 p. 95). Nesse sentido, podemos pensar que o depoente caracteriza o dom como algo que vem de dentro de si, fazendo parte do processo pedagógico, e envolve a compreensão ativa e responsiva, cujo papel é definir em si qual o tipo de profissional da Educação que deseja ser. Reflitamos sobre esta afirmação de Freitas (2013, p. 95): "Escrevo este texto a partir do lugar no qual me situo: o de educadora." Essa fala discorre sobre a importância de ser educador e assumir a profissionalidade de professor. Não se trata de dom, mas de uma profissão que exige muito investimento.

De acordo com Dubar (2012, p. 354, grifos do autor),

há muito tempo, porém, certas atividades que proporcionam renda não são associadas a priori a essa definição "negativa", nem por aqueles que as exercem, nem por outros. Ainda que sejam chamadas genericamente de trabalho, essas atividades que possibilitam uma identificação positiva são, ao mesmo tempo, escolhidas (ou, pelo menos, entendidas como tal), autônomas (isto é, vividas desse modo) e abertas para carreiras (no sentido de uma progressão ao longo da vida). Essas atividades de trabalho, qualificadas de profissionais, são produtoras de obras, quer se trate de arte, artesanato, ciências ou outras atividades criadoras de algo de si, ou produtoras de serviços úteis a outro (médicos, jurídicos, educativos). Elas dão um sentido à existência individual e organizam a vida de coletivos. Quer sejam chamadas de "ofícios", "vocações" ou "profissões", essas atividades não se reduzem à troca econômica de um gasto de energia por um salário, mas possuem uma dimensão simbólica em termos de realização de si e de reconhecimento social.

\footnotetext{
9 "La identidad profesional docente es, también, fruto de un largo proceso de socialización que se culmina al ir ejerciendo la profesión y asumir la cultura profesional propria que hace sentirse y ser reconocido."

Revista Labor, V. 1, N. 25 DOI: https://doi.org/10.29148/labor.v1i25.60205 
Panda, ao utilizar o termo dom, poderia estar se referindo à didática docente, pois declarou que a sala de aula é um ótimo ambiente para aprender, mas disse que, fora dela, aprende-se muito mais, porque o professor e o aluno podem tratar de assuntos que, na sala de aula, não foram mencionados por falta de tempo ou oportunidade. Dessa forma, utiliza-se de outros ambientes, além da sala de aula, para ensinar, lidar e aprender com os alunos.

Podemos inferir dos depoimentos de Panda o reconhecimento de que os saberes dos professores não são apenas os acadêmicos e cognitivos, mas são também os da existência, visto que o docente atua com aquilo que experienciou. Ele pensa a partir de sua história de vida, com seus aspectos emocionais, afetivos, pessoais.

\begin{abstract}
O professor não é somente um "sujeito epistêmico" que se coloca diante do mundo em uma relação estrita de conhecimento, que "processa" informações extraídas do "objeto" (um contexto, uma situação, pessoas etc.) através de seu sistema cognitivo, indo buscar, por exemplo, em sua memória, esquemas, procedimentos, representações a partir dos quais organiza as novas informações. Ele é um "sujeito existencial" [...], uma pessoa completa, com seu corpo, suas emoções, sua linguagem, seu relacionamento com os outros e consigo mesmo. Ele é uma pessoa comprometida em e por sua própria história - pessoal, familiar, escolar, social - que Ihe proporciona um lastro de certezas a partir das quais ele compreende e interpreta as novas situações que o afetam e constrói, por meio de suas próprias ações, a continuação de sua história. (TARDIF; RAYMOND, 2000, p. 235, grifos dos autores)
\end{abstract}

Recair sobre nós as expectativas do outro não nos limita a transmitir conhecimento, porque ser professor é muito mais do que isso. Ser professor é assumir que temos a responsabilidade pela transformação da sociedade, na qual as melhorias econômicas, políticas, sociais só virão para um povo culto, ou seja, que sabe o que precisa e que sabe cobrar por isso. Como afirma Marcelo (2009, p. 115), "a docência como profissão precisa rever-se e reconstruir-se para continuar cumprindo os compromissos morais que veio desenvolvendo: assegurar o direito de aprender de todos os meninos e meninas, adultos e adultas."

Além do compromisso político, a identidade profissional também requer a apropriação de um repertório de saberes para o exercício da docência. Tardif (2014) nos leva a pensar sobre os vários saberes que compõem o repertório do conhecimento profissional. Tais saberes contribuem na construção identitária dos docentes, pois incluem os conhecimentos pessoais, os da formação profissional, os da experiência, além dos instrumentais (livros, apostilas, programas etc.). 
Em relação ao lugar de aquisição dos saberes profissionais dos professores, esse processo não se restringe ao presente. Isso se deve ao conhecimento adquirido no contexto da vida pessoal, a sua trajetória escolar e ao percurso profissional serem constitutivos da identidade profissional do docente.

Nesse sentido, devem ser considerados os processos de socialização, pois, para Tardif e Lessard (2014), o histórico familiar, a formação, o ambiente de trabalho e a relação com os colegas contribuem para os saberes profissionais e justificam suas ações na docência. Marcelo (2009, p. 112, grifos do autor) afirma:

\begin{abstract}
É preciso entender o conceito de identidade docente como uma realidade que evolui e se desenvolve, tanto pessoal como coletivamente. A identidade não é algo que se possua, mas sim algo que se desenvolve durante a vida. [...] Sendo assim, a identidade pode ser entendida como uma resposta à pergunta "quem sou eu neste momento?" A identidade profissional não é uma identidade estável, inerente ou fixa. É resultado de um complexo e dinâmico equilíbrio onde a própria imagem como profissional tem que se harmonizar com uma variedade de papéis que os professores sentem que devem desempenhar.
\end{abstract}

A entrevista narrativa possibilita uma resposta a essa pergunta, pois, no momento de sua realização, o depoente reflete sobre sua trajetória, dá ao pesquisador pistas de como foi seu processo e atribui sentidos a sua experiência. No caso deste estudo, cada depoente narrou como foi essa trajetória, contou quais acontecimentos foram marcantes; e mesmo aqueles que aderiram à profissão por contingências da vida foram se identificando com a docência.

De acordo com Santos (2005, p. 130),

a socialização é, neste ponto de vista, um processo de construção identitária amplificado não só pela família ou pela escola, mas, de igual modo, pelo indivíduo que negocia e reinterpreta os vários sistemas tipificados, opções de conduta, ambivalências em sentimentos de pertença e referência, definindo uma identidade pessoal e uma forma singular de se mover e ler a realidade social.

Havia, de nossa parte, o interesse em compreender o que levou esses docentes a aceitarem permanecer na instituição contratados por tempo determinado. Constatamos que a mudança da contratação por tempo determinado para a efetivação não significou um entrave para a constituição profissional. Todos os professores afirmaram que a modalidade de contrato não interferiu em suas trajetórias profissionais. Atuar como temporário representou uma fase de aprendizagem até mesmo para ser aprovado no concurso por prazo indeterminado. O professor, 
Programa de Pós-graduação em Educação, Universidade Federal do Ceará

Fortaleza-CE-Brasil

contratado por tempo determinado espera pelo concurso público para se efetivar na própria instituição, porque só assim poderá participar da evolução funcional, até mesmo ampliar carga horária em outras escolas técnicas, desde que tenham aulas disponíveis, ou, ainda, participar de projetos, assumir coordenação de curso ou de projetos. Apesar de não terem uma formação voltada para o magistério, no ambiente escolar da Etec o professor é tratado, considerado e respeitado como professor, visto que na sala de aula, no momento que está lecionando, ele é professor porque cumpre um plano de aula, é cobrado pelo coordenador do curso e pelo diretor da escola e também pelos próprios alunos. Ele participa de reuniões pedagógicas e das visitas do conselho da CETEC, órgão que fiscaliza as escolas e os respectivos cursos. Essa não diferenciação entre as modalidades de contratação possibilita que o professor temporário conheça a cultura da instituição e sinta-se valorizado profissionalmente o que o mobiliza para aguardar a abertura de concursos. Águia (EN, 2018), por exemplo, afirmou:

Você tem esperança de algum concurso entrar. Olhando isso pelo lado de um indeterminado: "Agora eu concursei, estou de boa, não quero mais nada." São casos e casos, como também existem casos e casos de determinados. Teve determinados lá que não ficaram, porque jogaram a chance fora. Não sei se para ele era uma chance ou não. Para mim, era. Então, eu a abracei e falei: "é aqui que eu vou ficar. É aqui que eu vou mostrar meu trabalho."

Para a maioria desses professores, o repertório de saberes foi constituído no exercício da profissão, visto que nem todos tiveram uma formação voltada ao magistério. A aprendizagem para a docência ocorre, muitas vezes, pela observação, como aponta Marcelo (2009, p. 116): "Podemos afirmar, sem risco de nos equivocarmos, que a docência é a única das profissões em que os futuros profissionais se veem expostos a um maior período de observação não dirigida em relação às funções e tarefas que desempenharão no futuro." Há uma imersão no contexto de trabalho bem antes do início do exercício da atividade profissional.

Há também que se considerar se a escola na qual se atua possibilita essa constituição. Águia (EN, 2018), ao lembrar do início de sua atuação na escola, disse:

Então, você sabia que todo mundo estava engajado no projeto. Você chamava um projeto? Vamos trazer. Porque todo mundo tinha interesse em ficar. E a gestão que eu trabalhei sempre foi uma gestão aberta. Ela sempre deu possibilidades de construir. Era só construir com responsabilidade. Tinha gente que tinha muita responsabilidade, era uma escola nova, que estava crescendo. 
Joaninha (EN, 2018) também fez menção a seu início de carreira na instituição:

Então, a primeira coisa é passar no processo seletivo ou passar no concurso, a segunda é você montar a aula. Então, você chega com aquele papel que a unidade te dá, com todas as... Minha Etec é base tecnológica, desculpa, o componente curricular não é. Então, eu falo: "Beleza, e agora?" Aí eu sentei, fui pegando livro, indo para a biblioteca, que adoro uma biblioteca; então, eu fui tudo em cima de biblioteca, sites, peguei artigos e fui montando. É óbvio que, quando você entra, o seu primeiro semestre nunca vai ser legal, nunca. Por quê? Porque, embora você já esteja acostumada a dar aula há oito anos, é sempre uma novidade, é sempre diferente, porque, vamos dizer assim, até você preparar uma aula... A aula que eu preparei, por exemplo, o ano passado, se eu der a mesma aula na mesma disciplina para uma turma este semestre, ela é diferente, não adianta. Então, voltando como é que eu fui preparando. Eu preparei do jeito que eu gostaria de receber as informações, do jeito que eu gostaria de ser ensinada. Então, sempre que eu pego um tema, eu vou a fundo, eu leio, vejo o que dali é importante, que eu acho que tem a ver, a ligação com o curso no qual eu estou dando aula.

Nesse processo, a professora vai se constituindo, evidenciando que a identidade profissional não é estática. Marcelo afirma (2009, p. 114): “A identidade profissional docente é composta por subidentidades mais ou menos relacionadas entre si. Essas subidentidades têm relação com os diferentes contextos nos quais os professores se movimentam." Os professores vão aprendendo com os alunos, com os pares, buscando por cursos de formação continuada e vão se constituindo docentes do CPS. "Uma das chaves de identidade profissional docente é proporcionada, sem sombra de dúvida, pelo conteúdo que se ensina." (MARCELO, 2009, p. 118).

Podemos dizer que Panda gosta da ideia de lecionar. Sócrates adora estar em sala de aula, pois ressaltou as interações possíveis entre alunos e professores. Joaninha se sente realizada e acredita ter encontrado sua profissão. Cristal lembrou que tinha uma relação muito boa com outros professores. Por fim, Águia disse que não basta dar qualquer aula, é necessário ministrar uma aula sempre melhorada. Em síntese, os depoentes demonstraram satisfação e respeito pela profissão docente e revelaram indícios de como se constituíram docentes no exercício da profissão e nas relações com o outro - professores e alunos.

Há que se ressaltar que todos os docentes sinalizaram que, para eles, a contratação por tempo determinado não representou dificuldades; muito pelo contrário, foi a possibilidade de conhecerem a instituição e seus modos de funcionamento, construindo experiências para se submeterem a um concurso de efetivação. Além disso, há indícios de como as condições de trabalho no CPS 
favorecem a continuidade dos docentes no CPS, à espera da efetivação. Há um clima organizacional que possibilita a constituição de um coletivo de trabalho que tem metas em comum. Eles assumem o que Tardif e Lessard (2014, p. 50) denominam de status do trabalho: "o status remete à questão da identidade do trabalhador tanto dentro da organização do trabalho quanto na organização social, na medida em que essas funcionam de acordo com uma imposição de normas e regras que definem os papéis e as posições dos atores."

As unidades do CPS têm suas normas e regras, mas os docentes se sentem valorizados nos papeis que ocupam. Os professores constroem, no cotidiano de algumas escolas, as normas e os comportamentos esperados de quem atua nessa instituição. Eles relataram que há uma ajuda mútua entre os docentes do CPS. Eles mesmos se disponibilizam a ajudar outros professores. Um deles contou que recebeu ajuda de professores que tinham mais experiência, o que foi motivador para esse profissional. Há uma construção coletiva nas unidades do CPS, o que nem sempre ocorre em outras modalidades de instituição com o professor temporário; e isso é fundante na constituição identitária desses docentes. Eles assumem status em ser profissionais nessas redes.

\section{Considerações finais}

As vozes dos professores aqui apresentadas sinalizam as boas condições de trabalho nas escolas dessa rede de ensino técnico profissionalizante em nível médio, o que os levou a permanecerem nas instituições em caráter temporário até a efetivação por concurso público. Esses indícios apontam o quanto as condições de trabalho podem ser favoráveis à constituição identitária de um professor que, mesmo não tendo uma formação específica para o exercício da profissão, acaba se identificando com ela. A maioria não tinha intenção de ser professor, mas, ao ingressar no CPS, aderiu à profissão e se empenhou para conseguir nela permanecer. Os saberes necessários ao exercício da prática docente foram sendo construídos na relação com os alunos e os colegas das unidades onde atuam. Por isso, no decorrer da prática docente, eles adquirem saberes para lidar com as questões atuais do ensino técnico, que envolve estudantes que buscam ingressar no mundo do trabalho. Esses professores relataram as parcerias existentes nas escolas e o trabalho coletivo, 
o que favorece uma identidade institucional; eles se sentem integrados no contexto profissional e sabem que podem contar com os colegas.

Não houve relatos de problemas nas relações professor-aluno, embora os docentes tenham relatado sobre os desafios que enfrentam diante do novo perfil de aluno que chega ao ensino médio. No entanto, não podemos desconsiderar que são alunos que se submeteram a um rigoroso processo seletivo, com muitos candidatos por vaga, o que significa que as escolas do CPS trabalham com um perfil privilegiado de estudantes. Há que se levar em conta que a sociedade está em constante transformação, e os adolescentes e jovens também. Isso coloca os professores em contínuos desafios de seguir aprimorando suas práticas e ampliando seu repertório de saberes, que vão além dos acadêmicos.

Em que pese a identidade pessoal não se separar da profissional, há que se considerar que a última está ligada ao mundo do trabalho. No caso dos professores do CPS, a maioria é composta por técnicos que aderiram à docência e, no decorrer do tempo, constituíram-se como docentes. São profissionais que, no percurso da vida, ingressam na escola técnica e se constituem e assumem a profissão docente. São profissionais com um saber marcadamente técnico e que, nas suas entrevistas não explicitaram que outro tipo de saber seria necessário para o exercício da docência. Adquiriram saberes pragmáticos (TARDIF; RAYMOND, 2000) que Ihes permitem desempenhar suas funções como professores. É como se os demais saberes necessários à docência, como aponta Tardif (2014), principalmente os saberes pedagógicos, não fossem condição para o exercício profissional.

Sócrates e Joaninha fizeram licenciatura; já Cristal, Panda e Águia não. Mas todos aderiram à profissão, passando pela socialização profissional (DUBAR, 2012), e foram edificando sua identidade docente no trabalho no CPS. Constituem-se no movimento de interação ao ensinar e aprender com os alunos, consigo mesmo e, de modo geral, com o outro, o processo de identidade profissional forma-se nos professores do CPS. Eles se sentem com status (TARDIF; LESSARD, 2014) por fazer parte do corpo docente do CPS.

Nas histórias de Panda, Cristal, Joaninha, Sócrates e Águia, identificamos suas relações familiares, suas escolhas e suas buscas pela profissão e pela estabilidade profissional. Podemos dizer que são professores que se sentem realizados na instituição e buscam construir projetos colaborativamente. Eles 
assumem a identidade como docentes e percebem uma identidade profissional institucional, marcada por um coletivo de trabalho, o que nem sempre ocorre em outras instituições de ensino.

\section{Referencias Bibliográficas}

BOLÍVAR, Antonio. La identidad profesional del profesorado de secundaria: crisis y reconstrucción. Málaga: Ediciones Aljibe, 2006.

BRUNET, Luc. Clima de trabalho e eficácia da escola. In: NÓVOA, António (org.). Organizações escolares em análise. Lisboa: Dom Quixote, 1992. p. 125-126.

DOMINICÉ, Pierre. O processo de formação e alguns dos seus componentes relacionais. In: NÓVOA, António; FINGER, Mathias (org.). 0 método (auto)biográfico e a formação. Natal: EDUFRN; São Paulo: Paulus, 2010. p. 81-95.

DUBAR, Claude. A construção de si pela atividade de trabalho: a socialização profissional. Caderno de Pesquisa, São Paulo, v. 42, n. 146, p. 351-367, maio/ago. 2012.

FREIRE, Paulo. Pedagogia da Autonomia: saberes necessários à prática educativa. 60. ed. São Paulo: Paz e Terra, 2019.

FREITAS, Maria Teresa de Assunção. Implicações de ser no mundo e responder aos desafios que a educação nos apresenta. In: Bakhtin. Belo Horizonte: Autêntica, 2013. p. 95-106. Educação, arte e vida em JOSSO, Marie-Christine. Caminhar para si. Tradução: Albino Pozzer. Coordenação: Maria Helena Menna Barreto Abrahão. Porto Alegre: EDIPUCRS, 2010.

JOVCHELOVITCH, Sandra; BAUER, Martin W. Entrevista narrativa. In: BAUER, Martin W.; GASKELL, George (ed.). Pesquisa qualitativa com texto: imagem e som: um manual prático. Tradução: Pedrinho A. Guareschi. 4. ed. Petrópolis: 2005. p. 90113.

MARCELO, Carlos. A identidade docente: constantes e desafios. Revista Brasileira de Pesquisa em formação docente, Belo Horizonte, v. 1, n.1, p. 109-131, ago./dez. $2009 . \quad$ Disponível em: https://revformacaodocente.com.br/index.php/rbpfp/article/view/8. Acesso em: 15 nov. 2019.

SANTOS, Clara. A construção social do conceito de identidade profissional. Revista Interacções, Santarém, n. 8, p. 123-144, 2005.

SÃO PAULO. Assembleia Legislativa do Estado de São Paulo. Decreto-Lei de 06 de outubro de 1969. Cria, como entidade autárquica, o Centro Estadual de Educação Tecnológica de São Paulo e dá providências correlatas. São Paulo: Assembleia Legislativa do Estado de São Paulo, [20--]. Disponível em: 
https://www.al.sp.gov.br/repositorio/legislacao/decreto.lei/1969/decreto.lei-0-

06.10.1969.html. Acesso em: 3 maio 2018.

TARDIF, Maurice. Saberes docentes e formação profissional. 16. ed. Petrópolis, RJ: Vozes, 2014.

TARDIF, Maurice; LESSARD, Claude. O trabalho docente: elementos para uma teoria da docência como profissão de interações humana. Tradução: João Batissta Kreuch. 9. ed. Petrópolis, RJ: Vozes, 2014.

TARDIF, Maurice; RAYMOND, Danielle. Saberes, tempo e aprendizagem do trabalho no magistério. Educação \& Sociedade, Campinas, ano XXI, n. 73, p. 209-244, dez. 2000.

\section{Viviane Cardoso Cunha de Lima}

São Paulo, São Paulo, Brasil

Atualmente a pesquisadora é professora de ensino médio técnico convocada para representar o Centro Paula Souza junto à Comissão de Execução de Desenvolvimento, de que trata o Decreto 60.089/2014 que dispõe sobre a implementação do sistema de gestão integrada de recursos humanos e de folha de pagamento-Gestão Integrada RH-Folh@ da Secretaria da Fazenda e Planejamento do estado de São Paulo.

E-mail: vcclima@hotmail.com

Link do Lattes: http://lattes.cnpq.br/5590943992538997

\section{Adair Mendes Nacarato}

Itatiba, São Paulo, Brasil

Graduada em Matemática pela Pontifícia Universidade Católica de Campinas (1975), mestre em Educação pela Universidade Estadual de Campinas (1994) e doutora em Educação pela Universidade Estadual de Campinas (2000). Atualmente é docente da Universidade São Francisco, campus de Itatiba, junto ao Programa de Pós-Graduação Stricto Sensu em Educação e ao curso de Pedagogia. Tem experiência na área de Educação, com ênfase em Educação Permanente, atuando principalmente nos seguintes temas: educação matemática, formação de professores, prática pedagógica e narrativas (auto)biográficas. Atua em cursos de extensão voltados à formação docente e ao desenvolvimento curricular em matemática. Realizou estágio de pós-doutoramento junto ao PPGE da UFRN no campo dos estudos biográficos, sob supervisão da Profa. Dra. Maria da Conceição Passeggi. É editora da Revista Horizontes. É pesquisadora produtividade/CNPq, nível 2. É líder dos grupos de pesquisa: Grupo Colaborativo em Matemática (Grucomat) e Histórias de Professores que Ensinam Matemática (HIFOPEM).

E-mail: ada.nacarato@gmail.com

Link do Lattes: http://lattes.cnpq.br/4651130852101924

\section{Recebimento: $26 / 07 / 2020$}

Aprovação: 13/04/2020 


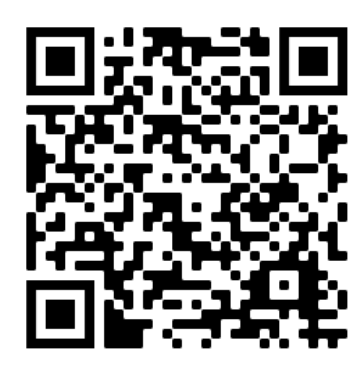

Q. Code

\section{Editores-Responsáveis}

Dr. Enéas de Araújo Arrais Neto, Universidade Federal do Ceará, UFC, Ceará, Brasil Dr. Sebastien Pesce, Universidade de Orléans, França 